九州大学学術情報リポジトリ

Kyushu University Institutional Repository

\title{
Mathematical Analysis on the Miscible Displacement and Diffusion of Dissolved Oxygen in the Submerged Soils
}

Phuc, Nguyen

Laboratory of Irrigation Engineering, Faculty of Agriculture, Kyushu University

Tanabe, Kunimi

Laboratory of Irrigation Engineering, Faculty of Agriculture, Kyushu University

Kuroda, Masaharu

Laboratory of Irrigation Engineering, Faculty of Agriculture, Kyushu University

https://doi.org/10.5109/22888

出版情報：九州大学大学院農学研究院紀要. 20 (2)，pp.61-73，1976-02. Kyushu University バージョン：

権利関係 : 
J. Fac. Agr., Kyushu Univ., 20, 61-73 (1976)

\title{
Mathematical Analysis on the Miscible Displacement and Diffusion of Dissolved Oxygen in the Submerged Soils
}

\author{
Nguyen Phuc, Kunimi Tanabe and Masaharu Kuroda \\ Laboratory of Irrigation Engineering, Faculty of Agriculture, \\ Kyushu University, Fukuoka
}

(Received August 8, 1975)

\begin{abstract}
The submerged paddy soils are characterized by the very small oxygen concentration throughout the soil profile. The oxidized zone below the ground surface has the thickness which depends on the chemical and biological circumstances of the soil medium.

In the paddy field, dissolved oxygen in the overlying flooding water can be transferred into the submerged soil by miscible displacement and diffusion. The phenomenon of miscible displacement takes place when dissolved oxygen in the percolating water is transferred through the soil medium by mass transport and by diffusion. The mathematical models of miscible displacement and diffusion are used to elucidate the mechanism of dissolved oxygen in the submerged soils. As for the various acceptable models, three are concerned. For model (1) and model (2), the results are very fitting between the calculations from the theoretical solutions and the experiments by using the long column of submerged sand in the laboratory. For model (3), the calculated results bring again a very meaningful interpretation for the vertical distribution of DO in the submerged media, when DO in the overlying flooding water is the indefinite function of time. Particularly, for the submerged clayey paddy soil, in which, the percolating velocity is very small and the consumption rate of oxygen is very large.

Since the growth of horizontal roots of rice plants may rely on dissolved oxygen, the present of which in the surface flooding water and in the oxidized zone of submerged soil is essential.
\end{abstract}

\section{INTRODUCTION}

The miscible displacement in porous media is a process that occurs when a solute in the displacing fluid is transferred through the medium by mass transport of moving fluid and by diffusion. In agriculture, this phenomenon can be seen under the movement of water containing dissolved oxygen (DO), fertilizer, herbicide or any other solutes. into and through the soil. When the effect of mass transport due to the flow velocity is negligible, the phenomenon takes place as the diffusion only.

The theoretical considerations and experimental performances of miscible displacement and diffusion have been made by many workers such as NieIsen and Biggar (1961), Brenner (1962), Papendick and Runkels (1965), Lindstrom et al. (1968), Rose and Passioura (1971), Smith et al. (1973) and Saxena et al. (1974). Particularly, Scott and Evans (1955), Patrick and Sturgis (1955), Bouldin (1968), Howeler and Bouldin (1971) and Takai et al. (1974) have worked to study the 
diffusion of oxygen in saturated soils.

In this study, the mathematical models for miscible displacement and diffusion of oxygen in the submerged soils are mentioned. Especially, in the submerged soil of the paddy field, where the requirement of oxygen of rice roots and soil microorganisms is very important, a large oxygen consumption rate and a small percolating velocity are introduced into the concerned equations.

The calculations from the solutions of the theoretical differential equations will be verified by the results of the experimental measurements in the laboratory.

\section{MATHEMATICAL MODELS}

The partial differential equation describing the miscible displacement of DO in the one-dimentional homogeneous submerged soil can be written as follows:

$$
\frac{\partial C}{\partial t}=D \frac{\partial^{2} C}{\partial z^{2}}-V \frac{\partial C}{\partial z}-R\left(C-C_{m}\right)
$$

where, $C$ is DO concentration in the submerged soil, $t$ is time, $z$ is depth in the flow direction, $D$ is diffusivity of DO, $V$ is average pore velocity and $R(C$ $-C_{m}$ ) is a factor representing the oxygen consumption in the soil due to the chemical and biological absorptions. $R$ is defined as the consumption rate and the term $\left(C-C_{m}\right)$ is used in Eq. (1) instead of $C$ only to express the DO value in the submerged soil never falls down less than a minimum value $C_{m}$ and to facilitate the calculation work from the solutions.

When the term of velocity $V$ is neglected, Eq. (1) reduces the equation of diffusion as follows:

$$
\frac{\partial C}{\partial t}=D \frac{\partial^{2} C}{\partial z^{2}}-R\left(C-C_{m}\right)
$$

The average pore velocity $V$ can be decided from the relation: $V=V_{d} / p$, where $V_{d}$ is the Darcy velocity and $p$ is water filled porosity of the soil. For the sands of particles $0.07 \mathrm{~mm}$ and $2.36 \mathrm{~mm}, p$ has the values of 0.43 and 0.48 , respectively.

In order to decide the diffusivity $D$, a case of miscible displacement without consumption rate $R$ is considered:

$$
\frac{\partial C}{\partial t}=D \frac{\partial^{2} C}{\partial z^{2}}-V \frac{\partial C}{\partial z}
$$

From Eq. (3), the value of $D$ can be deduced:

$$
D=\left(1-C_{m} / C_{0}\right)^{2} V L /\left(4 \pi S^{2}\right)
$$

In Eq. (4) $C_{0}$ is the initial DO concentration in the submerged column, $C_{m}$ is the minimum value of DO concentration, $L$ is a definite distance in the column at a definite period of time later when $C$ attains the value $C_{0}$ or when the ratio $C / C_{0}$ is equal to unity as shown in Fig. $1, \mathrm{~B}, S$ is the slope of the breakthrough curve which is graphed from the experimental data.

To evaluate the consumption rate $R$, the diffusivity $D$ is cancelled from the 


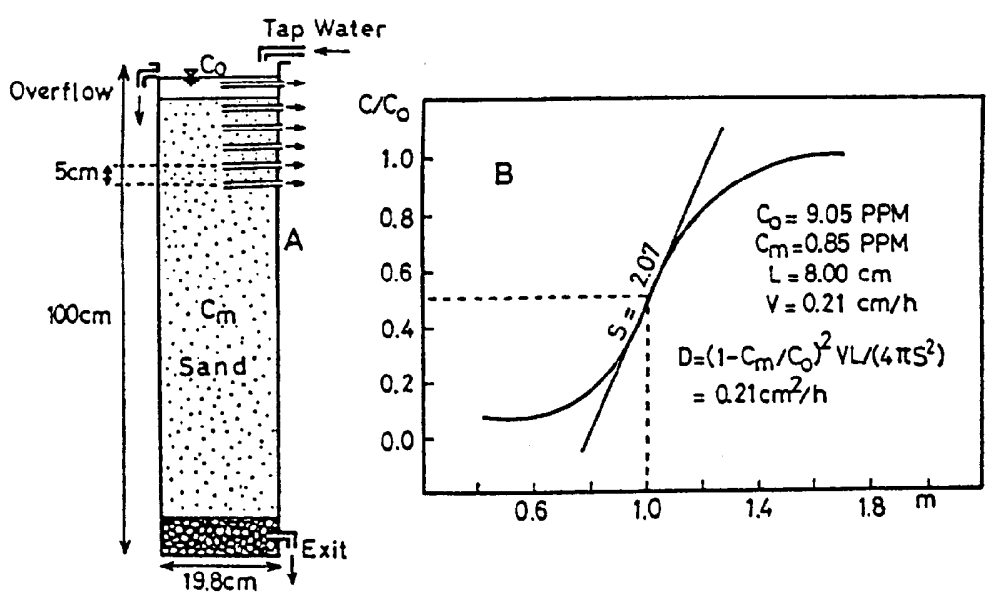

Fig. 1. Submerged column of porous materials for experiment and experimental evalution of diffusivity $D$. A, outline and scale of apparatus; B, evaluated diffusivity $D$.

diffusion equation, then Eq. (2) can be rewritten:

$$
\frac{d C}{d t}=-R\left(C-C_{m}\right)
$$

This equation has a special solution which is used to calculate the value of consumption rate $R$ :

$$
\left(C-C_{m}\right) /\left(C_{0}-C_{m}\right)=\exp (-R t)
$$

Some values of $R$ are calculated in Figs. 2 and 3.

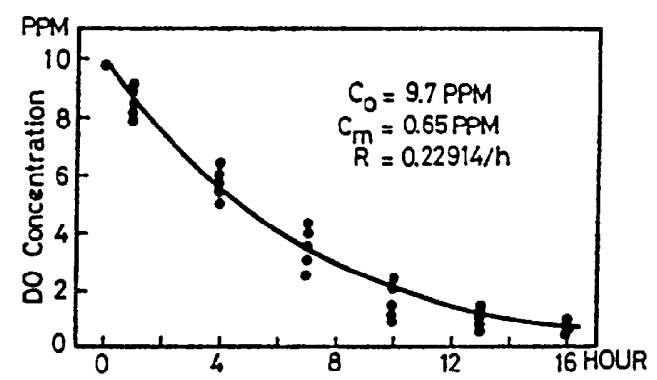

Fig. 2. Experimental consumption rate $R$ in sand of diameter $0.85-2.36 \mathrm{~mm}$.

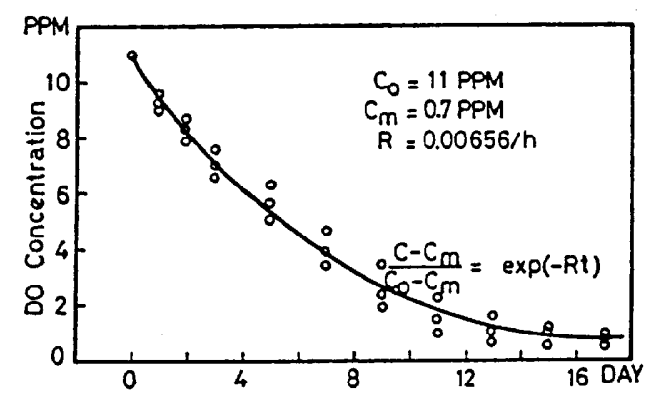

Fig. 3. Experimental consumption rate $R$ in a mixture of sand and clayey soil. 


\section{SOLUTIONS OF THE DIFFERENTIAL EQUATIONS}

The partial differential equations describing the miscible displacement: Eq. (1) and diffusion: Eq. (2) can be solved under various models that depend on different boundary and initial conditions.

(a) Model (1)

With the boundary and initial conditions:

$$
\left.\begin{array}{l}
C(0, t)=C_{0} \\
C(\infty, t)=C_{m} \\
C(z, 0)=C_{m}
\end{array}\right\}
$$

Place $C^{*}=C-C_{m}$, Eq. (8) is obtained from Eq. (1):

$$
\frac{\partial C^{*}}{\partial t}=D \frac{\partial^{2} C^{*}}{\partial z^{2}}-V \frac{\partial C^{*}}{\partial z}-R C^{*}
$$

Using Laplace transformation with $J(z, s)$ and $s$ are Laplace transforms of $C^{*}(z, t)$ and $t$, respectively, Eq. (8) can be rewritten:

$$
\frac{d^{2} J}{d z^{2}}-\frac{V}{D} \frac{d J}{d z}-(s+R) \frac{J}{D}=0
$$

with the conditions:

$$
\left.\begin{array}{l}
J(0, s)=\left(C_{0}-C_{m}\right) / s \\
J(\infty, s)=0
\end{array}\right\}
$$

The solution of Eq. (9) with its conditions in Eq. (10) is:

$$
\begin{aligned}
J(z, s) & =A \exp \left\{\frac{V z}{2 D}-\frac{z}{2 D}\left[V^{2}+4 D(s+R)\right]^{1 / 2}\right\} \\
& +B \exp \left\{\frac{V z}{2 D}+\frac{z}{2 D}\left[V^{2}+4 D(s+R)\right]^{1 / 2}\right\}
\end{aligned}
$$

The condition $J(\infty, s)=0$ yields $B=0$ and condition $J(0, s)=\left(C_{0}-C_{m}\right) / s$ gives $A=\left(C_{0}-C_{m}\right) / s$. Thus, substituting the values of $A$ and $B$ into Eq. (11), performing the inverse Laplace transforms to find the value of $C^{*}(z, t)$, the final solution is:

$$
\begin{aligned}
C(z, t)= & C_{m}+\frac{1}{2}\left(C_{0}-C_{m}\right) \exp \left(\frac{V z}{2 D}\right)\left\{\exp \left(\frac{-z\left(4 D R+V^{2}\right)^{1 / 2}}{2 D}\right)\right. \\
& \operatorname{erfc}\left[\frac{z-t\left(4 D R+V^{2}\right)^{1 / 2}}{2(D t)^{1 / 2}}\right]+\exp \left(\frac{z\left(4 D R+V^{2}\right)^{1 / 2}}{2 D}\right) \\
& \left.\operatorname{erfc}\left[\frac{z+t\left(4 D R+V^{2}\right)^{1 / 2}}{2(D t)^{1 / 2}}\right]\right\}
\end{aligned}
$$

For the case of diffusion solution, the term of velocity $V$ in Eq. (12) is cancelled. 


\section{(b) Model (2)}

With the conditions:

$$
\left.\begin{array}{rl}
C(0, t) & =C_{0} \\
C(\infty, t) & =C_{m} \\
C(z, 0) & =a \exp (b z)+C_{L} \quad \text { for } 0<z<L \\
& =C_{m} \text { for } L<z<\infty
\end{array}\right\}
$$

In order to solve Eq. (1) with its conditions in Eq. (13), place:

$$
C^{*}=C-C_{m}
$$

and

$$
C^{*}(z, t)=U(z, t)+W(z, t)
$$

As $C^{*}(z, t)$ is separated into 2 parts of $U(z, t)$ and $W(z, t)$, the equations of model (2) i. e. [Eq. (1) and Eq. (13)] can be separated into 2 parts as follows:

$$
\begin{gathered}
\frac{\partial^{2} U}{\partial z^{2}}-\frac{V}{D} \frac{\partial U}{\partial z}-\frac{R}{D} U=\frac{1}{D} \frac{\partial U}{\partial t} \\
\left.\begin{array}{c}
U(0, t)=C_{0}-C_{m} \\
U(\infty, t)=0 \\
U(z, 0)=0
\end{array}\right\}
\end{gathered}
$$

and

$$
\left.\begin{array}{l}
\frac{\partial^{2} W}{\partial z^{2}}-\frac{V}{D} \frac{\partial W}{\partial z}-\frac{R}{D} W=\frac{1}{D} \frac{\partial W}{\partial t} \\
W(0, t)=0 \\
W(\infty, t)=0 \\
W(z, 0)=a \exp (b z)+C_{L} \quad \text { for } 0<z<L \\
=0 \quad \text { for } L<z<\infty
\end{array}\right\}
$$

Equation (16) is just identical to Eq. (8) with the same boundary and initial conditions, thus, the solution of Eq. (16) must be equal to Eq. (12) without the first single term $C_{m}$ at the right hand side.

In order to solve Eq. (18), place:

$$
W(z, t)=X(z, t) \exp \left(-R t+\frac{V z}{2 D}-\frac{V^{2} t}{4 D}\right)
$$

Equation (18) and its conditions in Eq. (19), then, can be expressed:

$$
\left.\begin{array}{rlr}
\frac{\partial X}{\partial t}=D \frac{\partial^{2} X}{\partial z^{2}} & \\
X(0, t) & =0 \\
X(\infty, t) & =0 \\
X(z, 0) & =\exp (-V z / 2 D)\left[a \exp (b z)+C_{L}-C_{m}\right] & \text { for } 0<z<L \\
& =0 \text { for } L<z<\infty
\end{array}\right\}
$$

According to Carslaw and Jaeger (1959), the solution of heat conduction in 
a semi-infinite column with initial temperature $f(x)$ and surface temperature zero is:

$$
\left.V(x, t)=\frac{1}{2(D t)^{1 / 2}} \int_{0}^{t} f(u)\left\{\exp \left[\frac{(x-u)^{2}}{4 D t}\right]-\exp \frac{-(x+u)^{2}}{4 D t}\right]\right\} d u
$$

Equation (21) has the similar solution as in Eq. (23), after performing the integrals the result is:

$$
\begin{aligned}
C(z, t)= & C_{m}+\frac{1}{2}\left(C_{0}-C_{m}\right) \exp (V z / 2 D)\left[\exp (-M z / 2 D) \operatorname{erfc} \frac{z-M t}{N}\right. \\
& \left.+\exp (M z / 2 D) \operatorname{erfc} \frac{z+M t}{N}\right]+\frac{1}{2}\left(C_{m}-C_{L}\right) \exp (-R t)\left[\operatorname{erf} \frac{z-V t-L}{N}\right. \\
& \left.-\operatorname{erf} \frac{z-V t}{N}+\exp (V z / D) \operatorname{erf} \frac{z+V t+L}{N}-\exp (V z / D) \operatorname{erf} \frac{z+V t}{N}\right] \\
& +\frac{1}{2} a \exp \left(-R t+b^{2} D t-b V t\right)\left\{\operatorname { e x p } ( b z ) \left[\operatorname{erf} \frac{z+2 b V t-V t}{N}\right.\right. \\
& \left.-\operatorname{erf} \frac{z+2 b V t-V t-L}{N}\right]+\exp (-b z+V z / D)\left[\operatorname{erf} \frac{z-2 b D t+V t}{N}\right. \\
& \left.\left.-\operatorname{erf} \frac{z-2 b D t+V_{t}+L}{N}\right]\right\}
\end{aligned}
$$

provided that $M=\left(4 D R+V^{2}\right)^{1 / 2}$ and $N=2(D t)^{1 / 2}$.

(c) Model (3)

Before solving the problem of model (3), a special solution of Eq. (1) is being considered with the following conditions:

$$
\left.\begin{array}{l}
C(0, t)=F(t) \\
C(\infty, t)=C_{m} \\
C(z, 0)=C_{m}
\end{array}\right\}
$$

The transform of the present problem is:

$$
\frac{\partial^{2} C^{*}}{\partial z^{2}}-\frac{V}{D} \frac{\partial C^{*}}{\partial z}-\frac{R}{D} C^{*}=\frac{1}{D} \frac{\partial C^{*}}{\partial t}
$$

with the conditions:

$$
\left.\begin{array}{l}
C^{*}(0, t)=F(t)-C_{m} \\
C^{*}(\infty, t)=0 \\
C^{*}(z, 0)=0
\end{array}\right\}
$$

The first boundary condition in Eq. (27) is transformed into Fourier series:

$$
F(t)-C_{n}=\frac{1}{2} A_{0}+A_{n} \cos (b t)+B_{n} \sin (b t)
$$

Equation (26) is solved with the conditions in Eq. (27) by the method of 
Laplace transformation.

The final result can be written:

$$
\begin{aligned}
C(z, t)= & C_{n}+\frac{1}{4} A_{0} \exp \left[\frac{V z}{2 D}-z\left(\frac{R}{D}+\frac{V^{2}}{4 D^{2}}\right)^{1 / 2}\right] \operatorname{erfc} \frac{z-t\left(4 D R+V^{2}\right)^{1 / 2}}{2(D t)^{1 / 2}} \\
+ & \frac{1}{4} A_{0} \exp \left[\frac{V z}{2 D}+z\left(\frac{R}{D}+\frac{V^{2}}{4 D^{2}}\right)^{1 / 2}\right] \operatorname{erfc} \frac{z+t\left(4 D R+V^{2}\right)^{1 / 2}}{2(D t)^{1 / 2}} \\
+ & A_{n} \exp \left[\frac{V z}{2 D}-t\left(R+\frac{V^{2}}{4 D}\right)\right] \operatorname{erfc} \frac{z}{2(D t)^{1 / 2}} \\
+ & {\left[B_{n}\left(R+\frac{V^{2}}{4 D}\right)-A_{n} b^{\prime}\right] \exp \left(\frac{V z}{2 D}\right) \int_{0}^{t} \sin \left[b^{\prime}(t-r)\right] } \\
& \exp \left[-r\left(R+\frac{V^{2}}{4 D}\right) \operatorname{erfc} \frac{z}{2(D r)^{1 / 2}} d r\right. \\
+ & {\left[A_{n}\left(R+\frac{V^{2}}{4 D}\right)+B_{n} b^{\prime}\right] \exp \left(\frac{V z}{2 D}\right) \int_{0}^{t} \cos \left[b^{\prime}(t-r)\right] } \\
& \exp \left[-r\left(R+\frac{V^{2}}{4 D}\right)\right] \operatorname{erfc} \frac{z}{2(D r)^{1 / 2}} d r
\end{aligned}
$$

with $b^{\prime}=n \pi / P, n=1,2,3, \cdots \cdots$ and $P$ is period ( $=48$ hours).

Model (3) is related to the conditions:

$$
\left.\begin{array}{rl}
C(0, t) & =F(t) \\
C(\infty, t) & =C_{m} \\
C(z, 0) & =a \exp (b z)+C_{L} \quad \text { for } 0<z<L \\
& =C_{m} \quad \text { for } L<z<\infty
\end{array}\right\}
$$

The transformed equation of model (3), as previously, can be separated into 2 parts:

$$
C^{*}(z, t)=U(z, t)+W(z, t)
$$

then the component equations are:

$$
\frac{\partial U}{\partial t}=D \frac{\partial^{2} U}{\partial z^{2}}-V \frac{\partial U}{\partial z}-R U
$$

with

$$
\begin{aligned}
& U(0, t)=F(t)-C_{m} \\
& U(\infty, t)=0 \\
& U(z, 0)=0
\end{aligned}
$$

and

$$
\frac{\partial W}{\partial t}=D \frac{\partial^{2} W}{\partial z^{2}}-V \frac{\partial W}{\partial z}-R W
$$

with 


$$
\left.\begin{array}{rl}
W(0, t) & =0 \\
W(\infty, t) & =0 \\
W(z, 0) & =a \exp (b z)+C_{L}-C_{m} \quad \text { for } 0<z<L \\
& =0 \quad \text { for } L<z<\infty
\end{array}\right\}
$$

Equation (32) is just equal to Eq. (26) and Eq. (34) to Eq. (18) with the similar dependent conditions for each case. Thus, the solution of Eq. (31) for $C^{*}(z, t)$ is the sum of those of Eq. (32) and Eq. (34). Place $M=\left(4 D R+V^{2}\right)^{1 / 2}$, $N=2(D t)^{1 / 2}, p=2(D u)^{1 / 2}$ and $b^{\prime}=n \pi / P$, the result is:

$$
\begin{aligned}
C(z, t)= & C_{m}+\frac{1}{2}\left(C_{m}-C_{L}\right) \exp (-R t)\left[\operatorname{erf} \frac{z-V t-L}{N}-\operatorname{erf} \frac{z-V t}{N}\right. \\
+ & \left.\exp \left(\frac{V z}{D}\right) \operatorname{erf} \frac{z+V t+L}{N}-\exp \left(\frac{V z}{D}\right) \operatorname{erf} \frac{z+V t}{N}\right]+\frac{a}{2} \exp \\
& \left(-R t+b^{2} D t-b V t\right)\left\{\exp (b z)\left[\operatorname{erf} \frac{z+2 b D t-V t}{N}-\operatorname{erf} \frac{z+2 b D t-V t-L}{N}\right]\right. \\
+ & \left.\exp \left(-b z+\frac{V z}{D}\right)\left[\operatorname{erf} \frac{z-2 b D t+V t}{N}-\operatorname{erf} \frac{z-2 b D t+V t+L}{N}\right]\right\} \\
+ & \frac{1}{4} A_{0} \exp \left(\frac{V z}{2 D}\right)\left[\exp \left(\frac{-M z}{2 D}\right) \operatorname{erfc} \frac{z-M t}{N}+\exp \left(\frac{M z}{2 D}\right) \operatorname{erfc} \frac{z+M t}{N}\right] \\
+ & \mathrm{A}_{n} \exp \left(\frac{V z}{2 D}-\frac{M t}{4 D}\right) \operatorname{erfc} \frac{z}{N}+\exp \left(\frac{V z}{2 D}\right)\left(A_{n} M^{2} / 4 D+b^{\prime} B_{n}\right) \int_{0}^{t} \cos \\
& {\left[b^{\prime}(t-u)\right] \exp \left(\frac{-M u^{2}}{4 D}\right) \operatorname{erfc} \frac{z}{p} d u+\exp \left(\frac{V_{z}}{2 D}\right)\left(B_{n} M^{2} / 4 D-b^{\prime} A_{n}\right) } \\
& \int_{0}^{t} \sin \left[b^{\prime}(t-u)\right] \exp \left(\frac{-M u^{2}}{4 D}\right) \operatorname{erfc} \frac{z}{p} d u
\end{aligned}
$$

The solutions of the 3 above models can be easily calculated by a high speed computer.

\section{MATERIALS AND METHODS}

In the laboratory, the vinyl chloride pipes of length one meter were used as shown in Fig. 1, A. At the upper part of the pipe, small glass tubes of five millimeters in diameter were inserted at the intervals of five centimeters along the pipe wall. At the lower end of the pipe, a layer of ten centimeters of glass bead was constructed. This layer was connected with the outlet which could be used to regulate the percolating velocity at desirable values. Before sand was added into the pipe, tap water was poured fully into the pipe, thus the air bubbles were eliminated from the column of the submerged sand.

At the temperature $16-18^{\circ} \mathrm{C}$ of the laboratory, the experimental measurements were performed for model (1) and model (2). The water sample was 

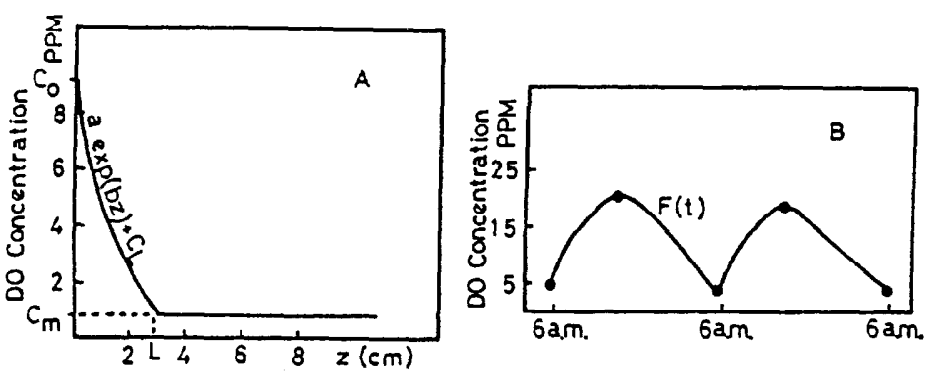

Fig. 4. Conditions in submerged soil. A, initial condition $(t=0)$;

$B$, boundary condition $(z=0)$.

pulled out from the submerged sand column and was transferred into a ready made small vessel of volume 5-6 cc for measuring the DO value. A thermometer was fixed firmly with the vessel to measure the temperature of the sample. In addition, a stirring bar of length five millimeters was put into the sample and the sensor of the DO meter was covered on the vessel upper end during the measurement. The vessel with sample, then, was placed on a magnetic stirrer. When the switch of the stirrer was put at position 'on', the stirring bar inside the sample was rotated and water sample was agitated, thus DO was read on the record dial of the amplifier unit.

(a) Model (1)

The boundary and initial conditions of model (1):

$$
\begin{aligned}
& C(0, t)=C_{0} \\
& C(\infty, t)=C_{m} \\
& C(z, 0)=C_{m}
\end{aligned}
$$

are shown in Fig. 5, A. To create the conditions (a), (b) and (c), tap water with constant oxygen concentration $C_{0}$ was allowed to flood at a depth of five centimeters upon the sand surface and overflow through a small hole. After a few weeks, usually $2-3$ weeks, the DO values in the sand column decrease to the minimum value $C_{m}$. However, in the distance of 1-5 centimeters below the water-sand interface, DO is greater than $C_{m}$ as a consequence of diffusion influence of DO from the overlying tap water.

In order to make the homogeneous $C_{m}$ throughout the sand column as indi-

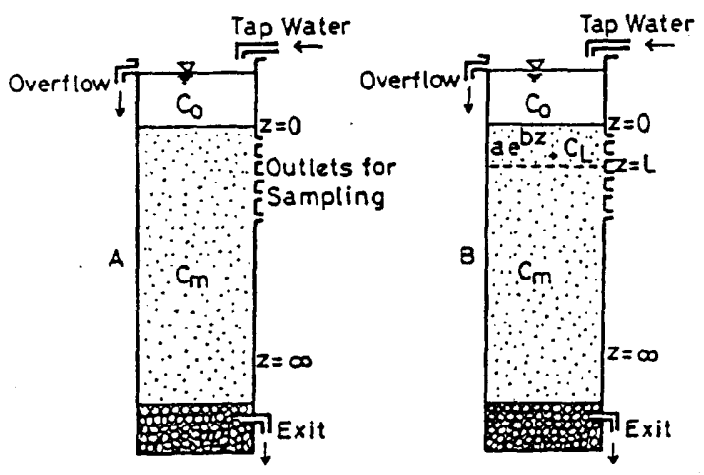

Fig. 5. The conditions of experiments. A, model (1); B, model (2). 
cated in condition (c), Pithophora, a green alga, is added into the tap flooding water. During the darkness, it must take some period of time before the DO value in tap flooding water gains the value $C_{\boldsymbol{m}}$.

Just before the experimental measurements begin, Pithophora is removed from the tap flooding water that is, then, substituted rapidly by new tap water of constant value $C_{0}$.

(b) Model (2)

The boundary and initial conditions of model (2):

$$
\begin{aligned}
C(0, t) & =C_{0} \\
C(\infty, t) & =C_{m} \\
C(z, 0) & \left.=a \exp (b z)+C_{L} \quad \text { for } 0<z<L\right\} \\
& =C_{m} \text { for } L<z<\infty
\end{aligned}
$$

are illustrated in Fig. 5, B, and can be easily created as model (1), except the addition of Pithophora into tap flooding water is not necessary, because there is already the oxidized zone $0<z<L$, [condition (c)] in the submerged sand column.

\section{RESULTS AND DISCUSSION}

\section{(a) The case of model (1) and model (2)}

Figures 6 and 7 demonstrate the experimental and calculated results of model (1) related to the solution in Eq. (12). The very near coincidence of two curve groups proves that the calculations from the theoretical model are suited very much with the results of experiment.

In these figures, the average pore velocity $V$ and diffusivity $D$ are nearly identical for both cases, whereas the consumption rate $R$ is different. In the sand of particle $0.85-2.36 \mathrm{~mm}$ in diameter, $R$ is $0.019 / \mathrm{h}$ and in one of $0.074-0.85$ $\mathrm{mm}$ in diameter, $R$ has the value of $0.007 / \mathrm{h}$. The size of sand particle directly relates to diffusivity $D$ rather than to the consumption rate $R$, which usually depends on the purity or dirtiness of the porous material.

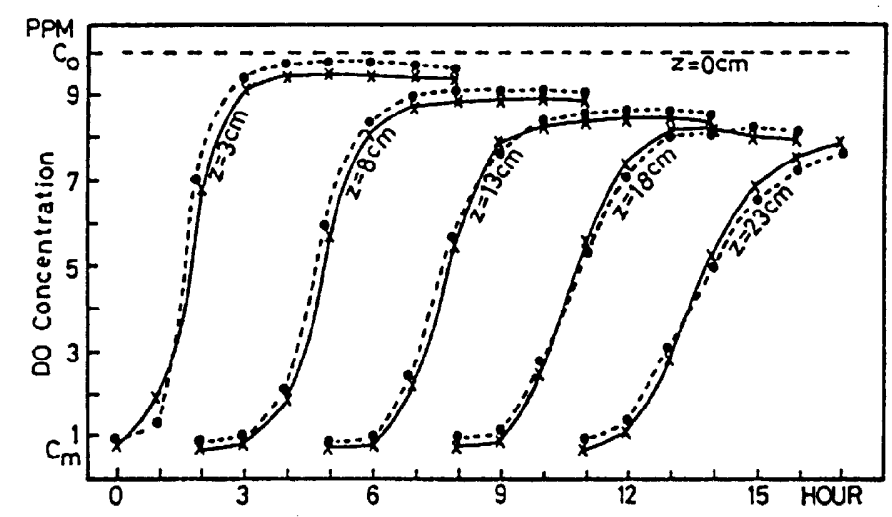

Fig. 6. Results of experiment and calculation of model (1). Sand particle, $0.85-2.36 \mathrm{~mm} ; V=1.69 \mathrm{~cm} / \mathrm{h} ; D=0.216 \mathrm{~cm}^{2} / \mathrm{h} ; R=0.019 / \mathrm{h}$. $x-x-x-$ experiment, - - - - - calculation by Eq. (12) 


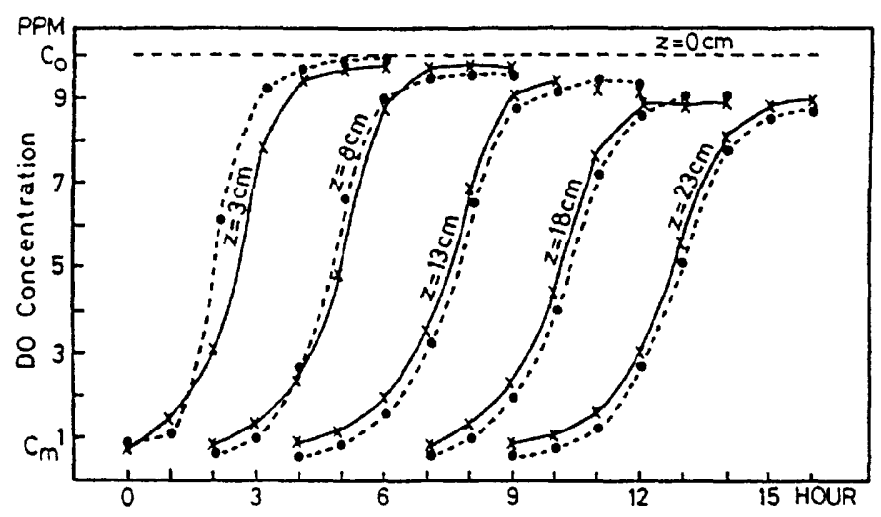

Fig. 7. Results of experiment and calculation of model (1). Sand particle, $0.07-0.85 \mathrm{~mm} ; V=1.749 \mathrm{~cm} / \mathrm{h} ; D=0.197 \mathrm{~cm}^{2} / \mathrm{h} ; R=0.007 / \mathrm{h}$. $-\times-\times-$ experiment, - ---•-- calculation by Eq. (12)

There are six curves which are graphed to represent the DO variation at six different positions along the sand column, including the uppermost curve at $z=0$. The maximum value of each curve never attains $C_{0}$, the value of DO in tap flooding water and decreases gradually according to the depth increase.

Figures 8 and 9 express the results of experiment and calculation of model (2) with the initial condition $C(z, 0)$ is a function of depth $z$.

As same as in the case of model (1), the theoretical curve group (dashed

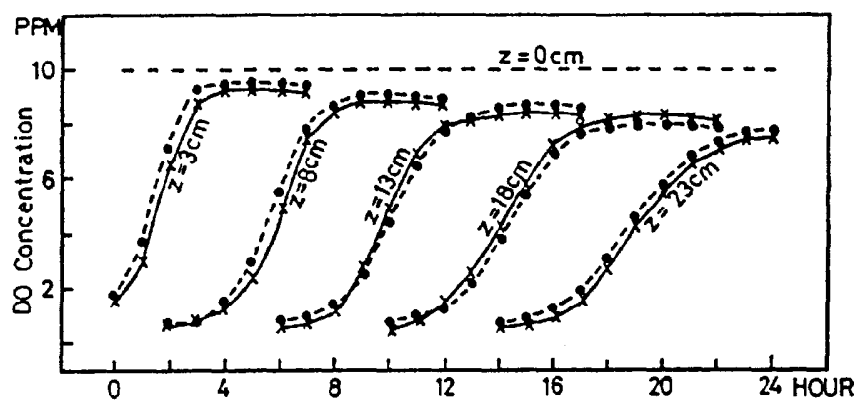

Fig. 8. Results of experiment and calculation of model (2). Sand particle, $0.85-2.36 \mathrm{~mm} ; V=1.144 \mathrm{~cm} / \mathrm{h} ; D=0.084 \mathrm{~cm}^{2} / \mathrm{h} ; R=0.014 / \mathrm{h}$. $-x-x-$ experiment, - - - - - - calculation by Eq. (24)

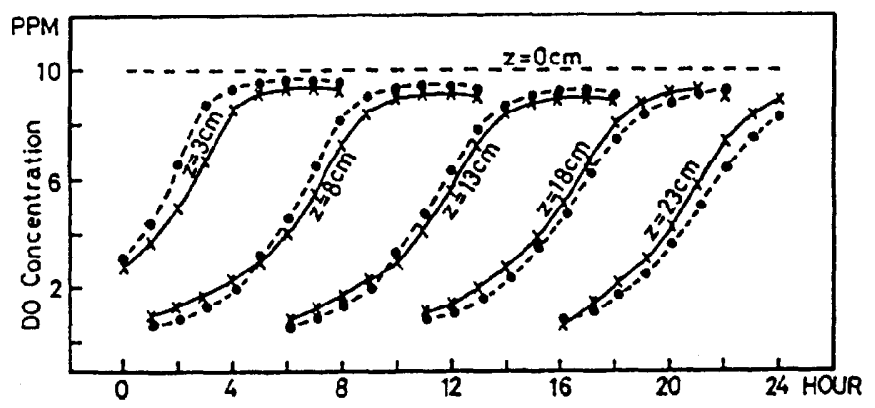

Fig. 9. Results of experiment and calculation of model (2). Sand particle, $0.07-0.85 \mathrm{~mm} ; V=1.1 \mathrm{~cm} / \mathrm{h} ; D=0.09 \mathrm{~cm}^{2} / \mathrm{h} ; R=0.004 / \mathrm{h}$. $-x-\times-$ experiment, - - - - - - calculation by Eq. (24) 
lines) calculated from the solution in Eq. (24) is very fitting with the experimental curve group (solid lines). There are also six positions along the sand column where the water samples are taken out for the measurement, including the position at $z=0$ with DO is constant $C_{0}$.

In Fig. 8 and Fig. 9, average velocity $V$ and diffusivity $D$ are nearly identical for both cases, $1.14 \mathrm{~cm} / \mathrm{h}$ and $1.1 \mathrm{~cm} / \mathrm{h}$ for $V$ and $0.084 \mathrm{~cm}^{2} / \mathrm{h}$ and $0.09 \mathrm{~cm}^{2} / \mathrm{h}$ for $D$. However, the diameter of sand particle $(0.85-2.36 \mathrm{~mm}$ and $0.074-0.85$ $\mathrm{mm})$ and consumption rate $R(0.014 / \mathrm{h}$ and $0.004 / \mathrm{h})$ are just different.

(b) The case of model (3)

Many trials have been done to test model (3) by the experimental works in the laboratory. In order to create the boundary condition which is a function $F(t)$ of time $t$ at $z=0$, Pithophora was added into the overlying flooding water of the sand column and incandescent light was used to create the change of DO in flooding water with time. But unfortunately, this work showed to be failed by the fact that it was impossible to cause the homogeneous values of DO along the profile of flooding water at the desirable instants, and the filaments of Pithophora tended to sink down into the underlying sand column. These resulted inexactly on the values of measurement.
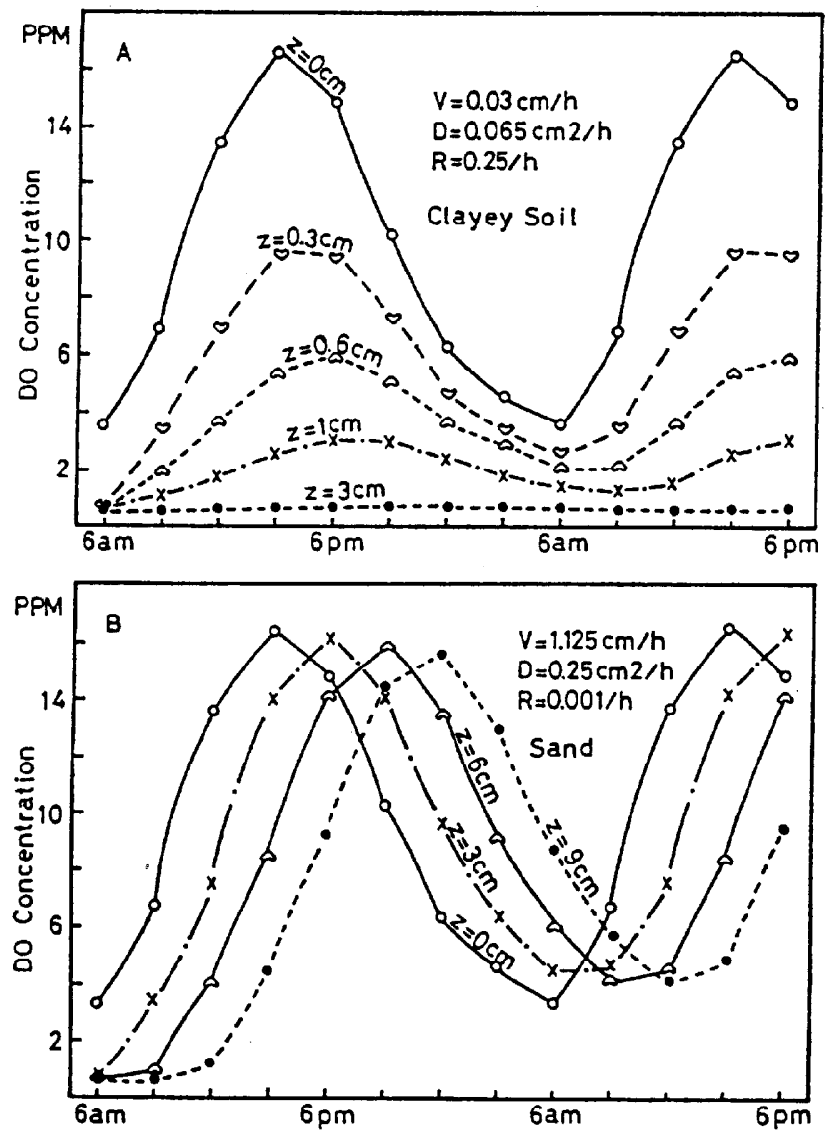

Fig. 10. Calculated results of model (3) from Eq. (36), boundary condition at $z=0$ measured in $\mathrm{Ly}_{1}$ on Aug. 13-14, 1974. A, the case for a clayey soil; $B$, the case of a sand. 
Nevertheless, the calculations of model (3) from the solution of Eq. (36) are completely meaningful as indicated in Fig. 10 ( $A$ and $B$ ).

For the case of sand, with high average pore velocity, $V=1.125 \mathrm{~cm} / \mathrm{h}$, and low consumption rate, $R=0.001 / \mathrm{h}$, the DO variations at five positions in the submerged sand column are nearly similar to that of the flooding water (Fig. 10, B). Whereas for the case of clayey paddy soil, with low average pore velocity, $V=0.0283 \mathrm{~cm} / \mathrm{h}$ or similar to a percolation rate in depth of $7 \mathrm{~mm} /$ day, and a very large consumption rate $R=0.25 / \mathrm{h}$, the DO curves at five positions in the column never cut the DO curve of the flooding water.

Figure 10, A illustrates the state of distribution of DO in the water-soil system of the normal paddy fields, where only 1-2 centimeters of the soil surface layer is oxidized versa the drastical reduced zone below.

\section{ACKNOWLEDGEMENTS}

The authors are indebted and want to express their profound gratitude to Dr. Prof. Shinya Ishio, Dr. Prof. Kohei Tanaka, Dr. Ass. Prof. Yushiro Motoda, Ass. Akira Tanaka and Mr. Kazuo Nishihara about their critical review of the manuscript and other precious advice and encouragement.

\section{REFERENCES}

Bouldin, D. R, 1968 Models for describing the diffusion of oxygen and other mobile constituents across the mud-water interface. J. Ecology, 56:77-87

Brenner, H. 1962 The diffusion model of longitudinal mixing in beds of finite length. Numerical values. Chem. Eng. Sci., $17: 229-243$

Carslaw, H. S. and J. C. Jaeger 1959 Conduction of heat in solids. Oxford Univ. Press, 2nd ed., 58-59

Howeler, R. H. and D. R. Bouldin 1971 The diffusion and consumption of oxygen in submerged soils. J. Ecology, 35: 202-208

Lindstrom, F. T., L. Boersma and H. Gardiner 1968 2,4-D diffusion in saturated soils: a mathematical theory. Soil Sci., 106: 107-113

Nielsen, D. R. and J. W. Biggar 1961 Miscible displacement in soils: I. Experimental information. SSSA. Proc., 25: 1-5

Papendick, R. I. and J. R. Runkles 1965 Transient-state oxygen diffusion in soil: I. The case when rate of oxygen consumption is constant. Soil Sci., 100:251-261

Patrick, W. H. J. and M. B. Sturgis 1955 Concentration and movement of oxygen as related to absorption of ammonium and nitrate nitrogen by rice. SSSA. Proc., 19:59-62

Rose, D. A. and J. B. Passioura 1971 The analysis of experiments on hydrodynamic dispersion. Soil Sci., 111 : 252-257

Saxena, S. K., L. Boersma, F. T. Lindstrom and J. L. Young 1974 Effect of pore size on diffusion coefficients in porous media. Soil Sci., 117: 80-86

Scott, A. D. and D. D. Evans 1955 Dissolved oxygen in saturated soil. SSSA. Proc., 19: 7-16

Smith I. M., R. V. Farraday and B. A. O'Connor 1973 Rayleigh-Ritz and Galerkin finite elements for diffusion-convection problems. Water Resour. Res., 9: 593-606

Takai, Y., H. Wada, H. Kagawa and K. Kobo 1974 Microbial mechanism of effects of water percolation on Eh, iron and nitrogen transformation in the submerged paddy soils. Soil Sci. Plant Nutr., $20: 33-45$ 